\title{
Experimental analysis for the dynamic initiation mechanism of debris flows
}

\author{
LI Chi1 ${ }^{1}$ http://orcid.org/oooo-ooo1-9150-7517; e-mail: nmglichi@gmail.com; tjdxlch2003@126.com
} ZHU Wen-hui' (D http://orcid.org/oooo-ooo1-5383-4859; e-mail: wenhui@imut.edu.cn

LI Lin² i http://orcid.org/oooo-ooo2-1317-4742; e-mail: lin.li@jsums.edu

LU Xiao-bing3 (iD http://orcid.org/oooo-0002-7371-0455; e-mail: xblu@imech.ac.cn

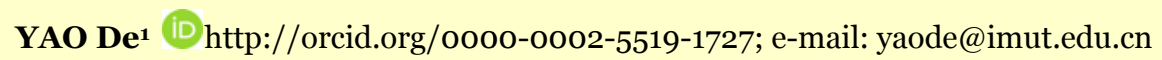

Farshad AMINI² (D) http://orcid.org/oooo-0oo3-2899-0045; e-mail: famini@jsums.edu

1 College of Civil Engineering, Inner Mongolia University of Technology, Inner Mongolia, Hohhot 010051, China

2 Department of Civil and Environmental Engineering, Jackson State University, Jackson, MS 39217, USA

3 Institute of Mechanics, Chinese Academy of Science, Beijing 10oo84, China

Citation: Li C, Zhu WH, Li L, et al. (2016) Experimental analysis for the dynamic initiation mechanism of debris flows. Journal of Mountain Science 13(4). DOI: 10.1007/s11629-014-3258-z

(C) Science Press and Institute of Mountain Hazards and Environment, CAS and Springer-Verlag Berlin Heidelberg 2016

\begin{abstract}
Debris flow is one of the major secondary mountain hazards following the earthquake. This study explores the dynamic initiation mechanism of debris flows based on the strength reduction of soils through static and dynamic triaxial tests. A series of static and dynamic triaxial tests were conducted on samples in the lab. The samples were prepared according to different grain size distribution, degree of saturation and earthquake magnitudes. The relations of dynamic shear strength, degree of saturation, and number of cycles are summarized through analyzing experimental results. The findings show that the gravelly soil with a wide and continuous gradation has a critical degree of saturation of approximately $87 \%$, above which debris flows will be triggered by rainfall, while the debris flow will be triggered at a critical degree of saturation of about $73 \%$ under the effect of rainfall and earthquake $(M>6.5)$. Debris flow initiation is developed in the humidification process, and the earthquake provides energy for triggering debris flows. Debris flows are more likely to be triggered at the relatively low
\end{abstract}

Reived: 26 August 2014

Revised: 3 May 2015

Accepted: 13 August 2015 saturation under dynamic loading than under static loading. The resistance of debris flow triggering relies more on internal frication angle than soil cohesion under the effect of rainfall and earthquake. The conclusions provide an experimental analysis method for dynamic initiation mechanism of debris flows.

Keywords: Mountain hazard; Debris flows; Initiation mechanism; Humidification process; Rainfall; Earthquake; Triaxial test

\section{Introduction}

Debris flows initiated by earthquake and rainfall may cause catastrophic damage. Debris flows areas are often located in earthquake zone (USGS 2011). The geographical distribution of debris flows source areas and earthquake zones indicates earthquake leads to the strength reduction of gravelly soil and accelerate the debris flows triggering. The earthquake caused rock structure to loosen, formed deep ravines, and 
activated debris flows initiation. The debris flows is likely to occur when gravelly soil is dynamically triggered with a certain degree of saturation. This possibility is explored in the paper through geotechnical tests.

There have been extensive researches on the landslides and rainfall-induced debris flows. However, very few studies have been conducted on earthquake-induced debris flows, especially on dynamic initiation mechanism of debris flows during the humidification process. Most previous researches focused on the initiated mechanism of rainfall-induced debris flows (Takahashi 1978; Anderson and Sitar 1995; Iverson 1997ab; Zhu and Anderson 1998; Major and Iverson 1999; Hu and Wang 2001; Takahashi 2007; Tang and Zhu 2009; Iverson 2010; McCoy et al. 2012; Wang and Zhang 2013; Kean et al. 2013). During the rainfall-induced initiation of debris flows, soil suction reduction causes less effective normal stress on the potential failure surface, which reduces the soil shear strength and trigger debris flows initiation. Significant loss of attraction from the soil matrix due to rainfall infiltration was considered to be the main factor contributing to rainfall-induced debris flows initiation (Chen and Lee 2000; Chen et al. 2004; Chen and Zhang 2006; Chen et al. 2010). Rainfall has been considered as a pre-condition of debris flows initiation, and the key contribution to landslide evolving into debris flows (Fleming et al. 1989; Hu et al. 2001; Wang and Sassa 2003; Wena and Aydinb 2005; David et al. 2009; Li et al. 2010). Steepness of the slope, particle size distribution and deposit thickness have been studied as the important triggering factors for landslide evolving into debris flows (Cui 1992, 1993; Gregoretti 2000a; Gregoretti 200ob; Chen et al. 2002; Tang and Liang 2008; Gregoretti and Dalla Fontana 2008; Wang et al. 2013). In recent years, the earthquakes take place frequently all over the world, and the debris flow initiation after earthquakes and earthquake-induced mountain disaster have been more concerned. (Cui et al. 2008; Tang and Liang 2008; Cui et al. 2009; Tang et al. 2009; Cui et al. 2010; Zhuang et al. 2010; Zhuang 2011; Zhu 2011; Wu et al. 2012; Wang et al. 2013; Cui et al. 2013). In addition, some researches have been explored on soil dynamic shear strength, and soil liquefaction has been determined as a factor to initiate debris flows during the earthquake. (Seed and Idriss 1971; Sassa 1984; Sladen et al. 1985; Dai et al. 1991, 1999; Sassa and Wang 2003; Luna et al. 2012). These previous researches indicate that debris flows initiation during the earthquake is caused by shear strength reduction of soil particles. The interlocking between soil particles loosens during the earthquake, and the compacted soil is relieved.

Li et al. (2010) and Zhu (2011) studied on debris flows translated from landslide in the rainfall through numerical simulation. The effects of slope gradient, rainfall intensity and degree of saturation of soil were analyzed. The results indicate that the pore water pressure was the highest at the slope toe, and decreased from the toe to the shoulder. The large horizontal displacements were mainly located close to the toe of slope. Therefore, with the increase of slope gradient, rainfall intensity and the degree of saturation, the stability of slope decreased gradually and activated the debris flows initiation. Li et al. (2013) studied the initiating process of slide slope evolving into debris flows through numerical simulation when soil particles were in the state of humidifying. When soil particles dropped on the inclined slope surface due to gravity, a stable slope was ultimately formed. The critical moisture content was suggested, and when the moisture content was higher than the critical state, the top soil along the slope began to slide down. When the moisture content increased up to fully saturated condition, the top soil moved quickly and the slope acted as fluid slide.

In this study, soils are sampled from the debris flows sources area after Wenchuan earthquake. Based on the previous researches (Li et al. 2010, 2013; Zhu 2011), the dynamic initiation mechanism of debris flows in the humidification process is explored through static and dynamic shear strength experiments. Rainfall is considered as a pre-condition of debris flows, and saturated terrain is a necessity to activate debris flows initiation. The earthquake provides dynamic excitation power to accelerate debris flows initiation. This is a geotechnical experimental simulation for soils in consideration of the effect of earthquake and rainfall. The rules of soil strength attenuation are summarized, and the dynamic initiation mechanism of debris flows is studied. A critical degree of saturation of soil is suggested, and debris flows will be initiated above this degree. The 
resistance to the debris flows initiation is analyzed between friction angle and cohesion of soils. All these conclusions provide an experimental basis to explore the dynamic initiation mechanism of debris flows.

\section{Materials}

\subsection{Field-collected soils}

Wenchuan earthquake took place on May 12, 2008 in the Beichuan County, Sichuan Province, China. The field soils were collected from loose particles in Weijia Groove which is debris flow source area after Wenchuan earthquake. Wenjia Groove is located in Renjiaping village, Beichuan County, southwest of Sichuan province, China and it is shown in Figure 1. The geographic coordinates is $104^{\circ} 26^{\prime} 27^{\prime \prime} \mathrm{E}$ and $31^{\circ} 48^{\prime} 48^{\prime \prime} \mathrm{N}$, adjacent to the Jianjiang River. The Groove has steep terrain and erosive tectonic geomorphology. In this humid subtropical climate environment, the average 30year rainfall is $1.4 \mathrm{~m}$ per year. The field collected soils have a wide and continuous gradation, and its grain size distribution is shown in Table 1.

\subsection{Laboratory-prepared soil samples}

Due to the limited amount of field-collected soils, three types of different soil samples were prepared in the laboratory test based on different grain compositions. The aim is to study the influence of grain size distribution on the dynamic initiation mechanism. Taking the grain size distribution of field-collected soil as a reference, the samples were prepared with the same unit

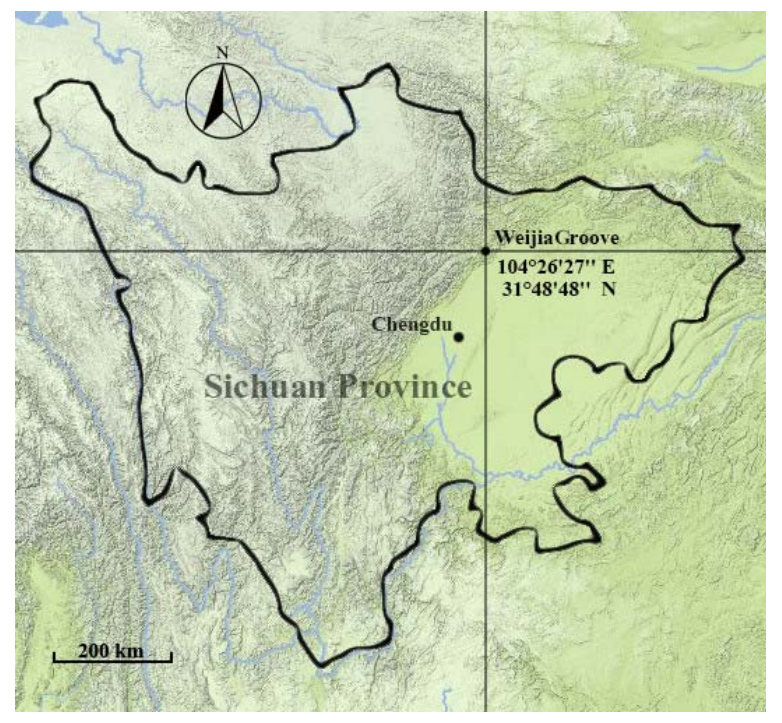

Figure 1 Geographical location of the Weijia Groove, Sichuan Province, China.

weight and similar grain size distribution of field collected soils. In the process of preparation, the large particles with diameter over $5 \mathrm{~mm}$ were removed from field-collected soils and replaced with particles in which grain size ranges from 2 $\mathrm{mm}$ to $4 \mathrm{~mm}$, to meet the requirements of laboratory experiment. It is named as sample A, and its grain size distribution is shown in Table 1. The coarse particles with grain size over $2 \mathrm{~mm}$ accounts for more than $50 \%$ in both sample A and field-collected soils, while the content of fine particles with grain size less than $0.1 \mathrm{~mm}$ are the same. Further, sample B and sample C were prepared representing different grain compositions in the laboratory preparation. Sample B was prepared with fine particles over $80 \%$ by weight, and sample $\mathrm{C}$ was prepared with coarse particles over $70 \%$ by weight in which grain size is greater than $2 \mathrm{~mm}$. So the grain composition of fine and

Table 1 Grain size distribution of field-collected soil and laboratory-prepared soil samples (Unit for grain size: $\mathrm{mm}$ )

\begin{tabular}{|c|c|c|c|c|c|c|c|}
\hline \multirow{2}{*}{\multicolumn{2}{|c|}{ Field-collected soil }} & \multicolumn{6}{|c|}{ Laboratory-prepared soil samples } \\
\hline & & \multicolumn{2}{|c|}{ Sample A } & \multicolumn{2}{|c|}{ Sample B } & \multicolumn{2}{|c|}{ Sample C } \\
\hline Grain size & $\%$ & Grain size & $\%$ & Grain size & $\%$ & Grain size & $\%$ \\
\hline $200 \sim 20$ & 24.1 & $5 \sim 2$ & 100 & $5 \sim 2$ & 100 & $5 \sim 2$ & 100 \\
\hline $20 \sim 5$ & 33.9 & $2 \sim 1$ & 49.93 & $2 \sim 1$ & 97.9 & $2 \sim 1$ & 25.4 \\
\hline $5 \sim 2$ & 11.4 & $1 \sim 0.5$ & 39.02 & $1 \sim 0.5$ & 94.5 & $1 \sim 0.5$ & 14.0 \\
\hline $2 \sim 1$ & 3.1 & $0.5 \sim 0.25$ & 30.62 & $0.5 \sim 0.25$ & 89.3 & $0.5 \sim 0.25$ & 5.25 \\
\hline $1 \sim 0.5$ & 6.1 & $0.25 \sim 0.1$ & 23.07 & $0.25 \sim 0.1$ & 85.8 & $0.25 \sim 0.1$ & $3 \cdot 5$ \\
\hline $0.5 \sim 0.25$ & 2.5 & $0.1 \sim 0.05$ & 16.78 & $0.1 \sim 0.075$ & 83.8 & $0.1 \sim 0.075$ & 1.75 \\
\hline $0.25 \sim 0.1$ & 2.3 & $0.05 \sim 0.025$ & 12.58 & $0.075 \sim 0.05$ & 83.2 & $0.075 \sim 0.05$ & 0.87 \\
\hline $0.1 \sim 0.05$ & 4.0 & $0.025 \sim 0.01$ & 10.48 & $0.05 \sim 0.02$ & 82.3 & $<0.05$ & 0.1 \\
\hline $0.05 \sim 0.005$ & 6.9 & $0.01 \sim 0.005$ & 7.97 & $0.02 \sim 0.01$ & 81.4 & & \\
\hline$<0.005$ & 5.7 & $<0.005$ & - & $0.01 \sim 0.005$ & 80.1 & & \\
\hline
\end{tabular}


coarse particles is the main difference of three type samples. The dry unit weight and saturated moisture of three type samples are measured and listed in Table 2 according to Professional Standard of the People's Republic of China (SL237-1999). According to Unified Soil Classification System (USCS) (ASTM D2487-11), they are classified as silty gravel (GM), silty fine sand (ML) and wellgraded gravels (GW) for sample A, sample B and sample $\mathrm{C}$, respectively.

\section{Experimental Methods}

\subsection{Experimental instruments and sample preparation}

The testing system "GCTS_STX_100" was uses to conduct the static shear strength and dynamic shear strength tests in this study (Geotechnical Consulting and Testing Systems, STX_100 electro-hydraulic servo control bidirectional dynamic triaxial test system manual). of soil pressure) is more than 0.95 .

\subsection{Experimental procedure}

As shown in Table 3, there are two types of shear strength tests such as static and dynamic tests. The static and dynamic shear strength tests were conducted in the consolidated-undrained stress state (CU). Different moisture contents, different grain compositions and different static/cyclic stress are considered in the each test. The same displacement failure standard is adopted in the static and the dynamic tests, which indicates that the soil sample meets the displacement failure standard and the test is stopped when the axial strain reaches $5 \%$.

Firstly, soil samples with different moisture contents were consolidated, and then tested with static loading. The static shear strength of soil samples with different moisture contents can be determined. Mohr's circles are drawn in shear strength curves with major principle stress $\left(\sigma_{1}\right)$ and minor principle stress $\left(\sigma_{3}\right)$. Cohesion $\left(c_{s}\right)$ and inner
The soil specimens with 70 $\mathrm{mm}$ in diameter and $140 \mathrm{~mm}$ in height were prepared. The amount of water was premeasured and mixed with dry soil by proportionate weight to produce a homogeneous wet soil. The samples were compacted by layers within $70 \mathrm{~mm}$ diameter compaction molds. The effective consolidation pressure was $50 \mathrm{kPa}$ continuously for 24 hours to simulate consolidation pressure of soil on the slope surface. For saturated soil samples, saturated soil condition was achieved through applying back pressure on samples. The samples were considered saturated when the pore pressure coefficient B (a relationship between the increment of pore water pressure and the increment
Table 2 Soil mechanics properties of three types of soil samples

\begin{tabular}{|l|l|l|l|l|l|} 
Samples & $\begin{array}{l}\text { Grain size distribution (\%) } \\
\text { Coarse } \\
\text { particles } \\
(>2 \mathrm{~mm})\end{array}$ & $\begin{array}{l}\text { Fine } \\
\text { particles } \\
(<0.05 \mathrm{~mm})\end{array}$ & $\begin{array}{l}\text { Dry unit } \\
\text { weight } \\
\left(\mathrm{kN} / \mathrm{m}^{3}\right)\end{array}$ & $\begin{array}{l}\text { Saturated } \\
\text { moisture } \\
(\%)\end{array}$ & Classified \\
\hline Sample A & 50.1 & 12.6 & 18.6 & 15.0 & GM \\
\hline Sample B & 1.9 & 82.3 & 15.9 & 24.7 & ML \\
\hline Sample C & 74.6 & 0.1 & 16.8 & 19.6 & GW \\
\hline
\end{tabular}

Notes: (1) Saturated moisture is measured according to "Professional Standard of the People's Republic of China (SL237-1999), Specifications of Soil Test”; (2) The samples are classified according to the Unified soil classification system (USCS) (ASTM D2487-11)".

Table 3 Experimental procedure and details

\begin{tabular}{|c|c|c|c|c|}
\hline Samples & $\mathrm{MC}$ & SD & Experimental procedure & Nos. \\
\hline \multirow{10}{*}{ Sample A } & \multirow{2}{*}{7} & \multirow{2}{*}{47} & consolidation $\rightarrow$ static shear test & 3 \\
\hline & & & consolidation $\rightarrow$ dynamic shear test & 9 \\
\hline & \multirow{2}{*}{9} & \multirow{2}{*}{60} & consolidation $\rightarrow$ static shear test & 3 \\
\hline & & & consolidation $\rightarrow$ dynamic shear test & 9 \\
\hline & \multirow[b]{2}{*}{11} & \multirow[b]{2}{*}{73} & consolidation $\rightarrow$ static shear test & 3 \\
\hline & & & consolidation $\rightarrow$ dynamic shear test & 9 \\
\hline & \multirow{2}{*}{13} & \multirow{2}{*}{87} & consolidation $\rightarrow$ static shear test & 3 \\
\hline & & & consolidation $\rightarrow$ dynamic shear test & 9 \\
\hline & \multirow[b]{2}{*}{15} & \multirow[b]{2}{*}{100} & saturation $\rightarrow$ consolidation $\rightarrow$ static shear test & 3 \\
\hline & & & $\begin{array}{l}\text { saturation } \rightarrow \text { consolidation } \rightarrow \text { dynamic shear } \\
\text { test }\end{array}$ & 9 \\
\hline \multirow[b]{2}{*}{ Sample B } & \multirow[b]{2}{*}{24.7} & \multirow[b]{2}{*}{100} & saturation $\rightarrow$ consolidation $\rightarrow$ static shear test & 3 \\
\hline & & & $\begin{array}{l}\text { saturation } \rightarrow \text { consolidation } \rightarrow \text { dynamic shear } \\
\text { test }\end{array}$ & 9 \\
\hline \multirow[b]{2}{*}{ Sample C } & \multirow[b]{2}{*}{19.6} & \multirow[b]{2}{*}{100} & saturation $\rightarrow$ consolidation $\rightarrow$ static shear test & 3 \\
\hline & & & $\begin{array}{l}\text { saturation } \rightarrow \text { consolidation } \rightarrow \text { dynamic shear } \\
\text { test }\end{array}$ & 9 \\
\hline
\end{tabular}

Notes: $\mathrm{MC}=$ Moisture content (\%); $\mathrm{SD}=$ Degree of saturation (\%). 
friction angle $\left(\phi_{s}\right)$ can be calculated through shear strength curves. At least three soil samples are required in the static shear strength testing corresponding to three different confining pressures. Secondly, the dynamic shear strength test was performed on soil samples with certain moisture contents which the same as that in the static shear strength test to simulate different dynamic loading initiated by earthquake following the rainfall. The humidification process induced by rainfall was simulated using the different degrees of saturation of samples. The moisture content increased gradually from unsaturation to saturation. Soil sample A was prepared with five different moisture contents, i.e., $7 \%, 9 \%, 11 \%, 13 \%$, and $15 \%$. As shown in Table 3, when the moisture content of soil is $15 \%$, the degree of saturation of sample A is $100 \%$. And the degrees of saturation of sample A are $47 \%, 60 \%, 73 \%$ and $87 \%$ for according moisture contents of soil $7 \%, 9 \%, 11 \%$ and $13 \%$. Soil sample B and sample C were prepared with fully saturated moisture $24.7 \%$ and $19.6 \%$, respectively.

The dynamic initiation process induced by earthquake was simulated using the different dynamic shear stress. The dynamic shear strength is defined as dynamic stress at the failure under the certain number of cycles (Seed and Idriss 1971). In the dynamic testing, $1 \mathrm{~Hz}$ sine-wave cyclic loading was acted on the samples to simulate the earthquake along axial direction, where different numbers of cycles represent different earthquake magnitudes. At the failure, the certain numbers of cycles $\left(N_{f}\right)$ as $8,12,20$ and 30 are recorded to correspond to different earthquake magnitudes of 6.5, 7.0, 7.5 and 8.0. When $N_{f}$ reaches 50, it represents a higher earthquake magnitude (Seed and Idriss 1971).

In the dynamic shear strength test, firstly, the ratio of consolidation stress is determined through Eq. (1). When $k_{c}$ equals to 1.o, it is an isotropic consolidation. Otherwise, it is an anisotropic consolidation. In this study, the isotropic consolidation is conducted under $50 \mathrm{kPa}$ consolidation pressures. Secondly, the number of cycles is determined under the different dynamic stress with certain confining pressures. When the axial strain reaches $5 \%$ in this process, the samples meet the displacement failure standard and the test is stopped. At least three different dynamic stresses $\left(\sigma_{d 1}, \sigma_{d 2}, \sigma_{d 3}\right)$ are conducted under a certain confining pressure, and three different numbers of cycles can be recorded. Thirdly, the above testing procedure are repeated, dynamic stress testing are conducted under three different confining pressures $\left(\sigma_{3 c 1}, \sigma_{3 c 2}, \sigma_{3 c 3}\right)$. The relationship between number of cycles and dynamic stress is analyzed with three different confining pressures, and dynamic stress at the failure $\left(\sigma_{d 1 f}, \sigma_{d 2 f}, \sigma_{d d_{f} f}\right)$ can be determined with the certain number of cycles $\left(N_{f}\right)$ corresponding to three different confining pressures. So, the minimum amount of samples required in dynamic shear strength testing is nine. Finally, the axial stress $\left(\sigma_{l c 1}, \sigma_{l c 2}, \sigma_{l c 3}\right)$ can be calculated through Eq. (2-4) corresponding to different confining pressures $\left(\sigma_{3 c 1}, \sigma_{3 c 2}, \sigma_{3 c 3}\right)$ with the certain number of cycles $\left(N_{f}\right)$. Mohr's circles are drawn in shear strength curves with major and minor principal stress. Dynamic cohesive $\left(c_{d}\right)$ and dynamic friction angle $\left(\phi_{d}\right)$ can be obtained through shear strength curves.

$$
\begin{aligned}
& k_{c}=\frac{\sigma_{1 c}}{\sigma_{3 c}} \\
& \sigma_{1 c 1}=\sigma_{3 c 1}+\sigma_{d 1 f} \\
& \sigma_{1 c 2}=\sigma_{3 c 2}+\sigma_{d 2 f} \\
& \sigma_{1 c 3}=\sigma_{3 c 3}+\sigma_{d 3 f}
\end{aligned}
$$

\section{Results and Discussion}

\subsection{Variation of static shear strength}

The cohesion $\left(c_{s}\right)$ and friction angle $\left(\phi_{s}\right)$ of static shear strength were obtained through total stress analysis under different degrees of saturation. Test results are shown in Table 4. The relationship between cohesion /friction angle and degree of saturation for sample A is shown in Figure 2. Figure 2 indicates that when the degree of saturation increases from $47 \%$ to $73 \%$, the change of cohesion is not obvious. The cohesion decreases rapidly with a further increase in degree of saturation. Meanwhile, when degree of saturation increases from $47 \%$ to $87 \%$, there is a slight increase in friction angle. But the friction angle decreases sharply after the degree of saturation 
reaches $87 \%$. This indicates that it has a critical degree of saturation, i.e., approximately $87 \%$ in this study. The relation between cohesion /friction angle and degree of saturation is consistent with that of previous research results, although the value of critical degree of saturation is slightly different (Dai et al. 1999; Cheng et al. 2004; Zhuang 2011; Yang et al. 2011). At this critical degree of saturation, the grain interlocking was at the strongest condition, it will fall sharply after this critical degree of saturation. When sample A has a moisture content of $15 \%$, which indicates that the degree of saturation is $100 \%$, the cohesion and friction angle drop to the lowest level. At this time shear strength attenuates to its weakest level.

As a comparative analysis, the cohesion and friction angle of shear strength of saturated sample B and sample $\mathrm{C}$ were tested and listed in Table 4. Sample A, sample B and sample C, they are all in saturated state, but have different grain size distributions. Under saturated state, the shear strength of saturated sample A is the highest while sample B is the lowest. This may be explained by the fact that loose soil with majority of fine particles is easier to trigger debris flows in the rainfall (Zhuang 2011). Whereas, gravelly soil with majority of coarse particles presents higher grain interlocking in the

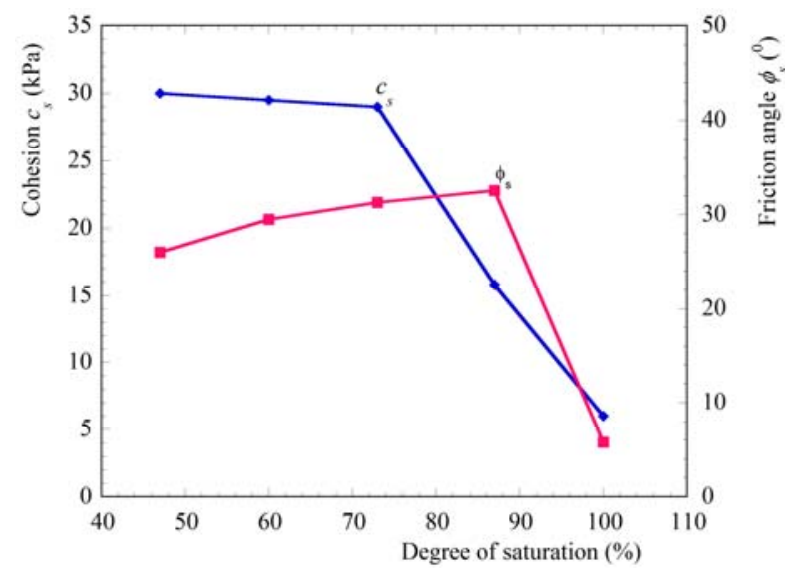

Figure 2 Cohesion $c_{s}$ and inner friction angle $\varphi_{s}$ various with degree of saturation for sample $A$.
Table 4 Static shear strength (cohesion/inner friction angle) at different degree of saturation

\begin{tabular}{|c|c|c|c|c|c|}
\hline \multirow{2}{*}{$\begin{array}{l}\text { Test } \\
\text { samples }\end{array}$} & \multirow{2}{*}{$\mathrm{MC}$} & \multirow{2}{*}{ SD } & \multirow{2}{*}{ PSD } & \multicolumn{2}{|c|}{ Static shear strength } \\
\hline & & & & $c_{s}(\mathrm{kPa})$ & $\varphi_{s}\left(^{(0}\right)$ \\
\hline \multirow{5}{*}{ Sample A } & 7 & 47 & $\begin{array}{l}250(100) \\
412(200) \\
562(300)\end{array}$ & 30.0 & 26.0 \\
\hline & 9 & 60 & $\begin{array}{l}320(100) \\
507(200) \\
738(300)\end{array}$ & 29.0 & 30.8 \\
\hline & 11 & 73 & $\begin{array}{l}326(100) \\
523(200) \\
758(300)\end{array}$ & 29.0 & 31.3 \\
\hline & 13 & 87 & $\begin{array}{l}281(100) \\
532(200) \\
747(300)\end{array}$ & 15.0 & 32.6 \\
\hline & 15 & 100 & $\begin{array}{l}51(100) \\
77(200) \\
96(300)\end{array}$ & 13.0 & 5.8 \\
\hline Sample B & 24.7 & 100 & $\begin{array}{l}27(100) \\
32(200) \\
52(300)\end{array}$ & 6.0 & $3 \cdot 3$ \\
\hline Sample C & 19.6 & 100 & $\begin{array}{l}36(100) \\
57(200) \\
80(300)\end{array}$ & 6.0 & 5.6 \\
\hline
\end{tabular}

Notes: (1) The third column is listed the principal stress difference at the certain confining pressure, the number in parenthesis represents the value of confining pressure. (2)When the axial strain reaches $5 \%$, the sample meets the displacement failure standard and the test is stopped. The principal stress differences are recorded. (3) $\mathrm{MC}=$ Moisture content (\%); SD = Degree of saturation (\%); PSD = Principal stress deviator $(\mathrm{kPa})$.

rainfall. Especially, gravelly soil with a wide and continuous gradation provides higher strength, i.e., saturated sample A has better stability than saturated sample $\mathrm{C}$ in the rainfall.

\subsection{Variation of dynamic shear strength}

The dynamic characteristics are obtained when sample $\mathrm{A}$ is loaded with confining pressure $\left(\sigma_{3 c}\right)$ of $100 \mathrm{kPa}$, and cyclic stress amplitude $\left(\sigma_{d}\right)$ of $98 \mathrm{kPa}$ at the moisture content of $11 \%$ (that is, degree of saturation is $73 \%$ ). The variation of pore water pressure vs. time, deviator stress vs. time, axial strain vs. time and deviator stress vs. axial strain (hysteresis loops) is shown in Figure 3 (a)(d), respectively. As shown in these figures, the initial dynamic pore water pressure increases gradually with time, there is a slight change in axial strain, and hysteresis loops are crowded together. Then there is a sharp increase in pore water pressure with time. The axial strain increases drastically up to the displacement failure standard. The hysteresis loops become sparser and their 

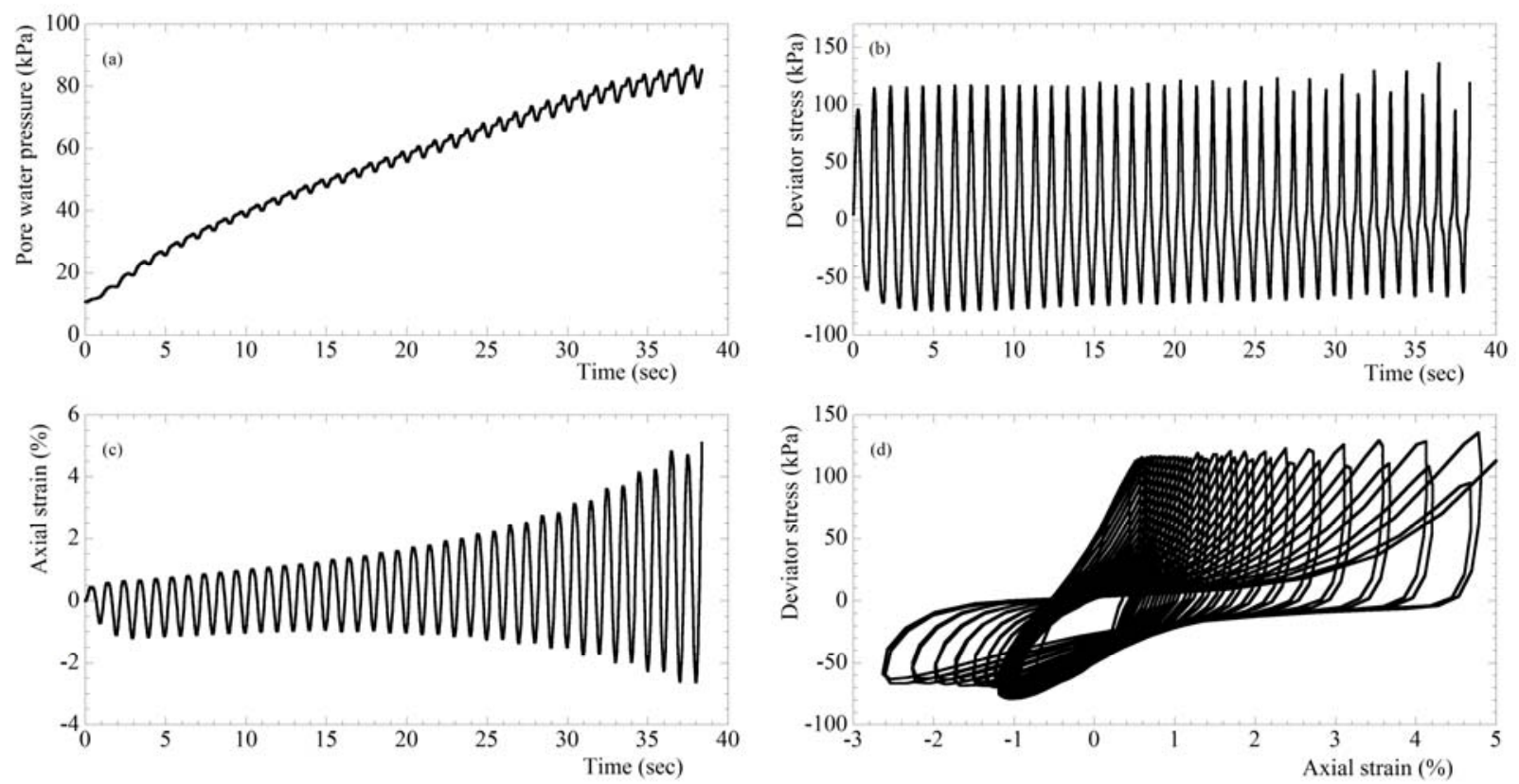

Figure 3 Dynamic characteristics on sample A with moisture content of 11\% (degree of saturation is $73 \%$ ) under confining pressure of $100 \mathrm{kPa}$ and cyclic stress amplitude of $98 \mathrm{kPa}$ : (a) pore water pressure, (b) deviator stress, (c) axial strain, and (d) hysteresis loops.

centers continue to move towards one direction until the sample reaches the failure point because of large displacement. During this process, the deviatory stress is held constant.

In the dynamic shear strength test, three same samples were prepared. After consolidation under an effective pressure of $50 \mathrm{kPa}$, three unequal cyclic stresses $\left(\sigma_{d 1}, \sigma_{d 2}, \sigma_{d 3}\right)$ were applied on these samples under certain confining pressure. The number of cycles up to failure $\left(N_{f}\right)$ could be determined when axial strain reaches displacement failure standard. The relationship between cyclic stress and number of cycles was summarized under three confining pressure of $100 \mathrm{kPa}, 200 \mathrm{kPa}$ and $300 \mathrm{kPa}$. The dynamic strength curves are shown in Figure 4 with different degree of saturation (e.g., (a)-(d)) and different grain size distribution (e.g., (e)-(g)). Then, dynamic shear strength was determined at different earthquake magnitudes through dynamic strength curves. When the confining pressure $\left(\sigma_{3 c}\right)$ was $100 \mathrm{kPa}, 200 \mathrm{kPa}$, or $300 \mathrm{kPa}$, the cyclic stress $\left(\sigma_{d}\right)$ was calculated under certain number of cycles $\mathrm{N}(=8,12,20,30,50)$ through dynamic strength curves. In Figure 4, the range of extrapolation for specific values of $\mathrm{N}(=8$, $12,20,30,50)$ was marked using yellow lines. And test curves have been processed through technique of extrapolation. The dotted lines on these curves are drawn to obtain the cyclic stress $\left(\sigma_{d}\right)$ at specific values of $\mathrm{N}(=8,12,20,30,50)$. If the confining pressure $\left(\sigma_{3 c}\right)$ was not shown in Figure 4 , the cyclic stress $\left(\sigma_{d}\right)$ was obtained through interpolation method from the dynamic strength curves.

The dynamic shear strength, cohesion $\left(c_{d}\right)$ and friction angle $\left(\phi_{d}\right)$ are analyzed with different degree of saturation for these three types of samples and shown in Table 5. Comparing Table 5 with Table 4 , the dynamic shear strength $\left(c_{d}\right.$ and $\left.\phi_{d}\right)$ of samples are less than its corresponding static shear strength $\left(c_{s}\right.$ and $\left.\phi_{s}\right)$ because the dynamic loading destroys the soil structure causing shear strength to decrease. The degree of attenuation varies with degree of saturation, grain size distribution and earthquake magnitudes.

\subsection{Dynamic shear strength attenuation mechanism}

The relationship between dynamic shear strength $\left(c_{d}\right.$ and $\left.\phi_{d}\right)$ and degree of saturation, number of cycles and grain size distribution is summarized and shown in Figures 5, 6 and 7. As shown in Figure 5 (a) and Figure 5 (b), the influence of degree of saturation on the cohesion 

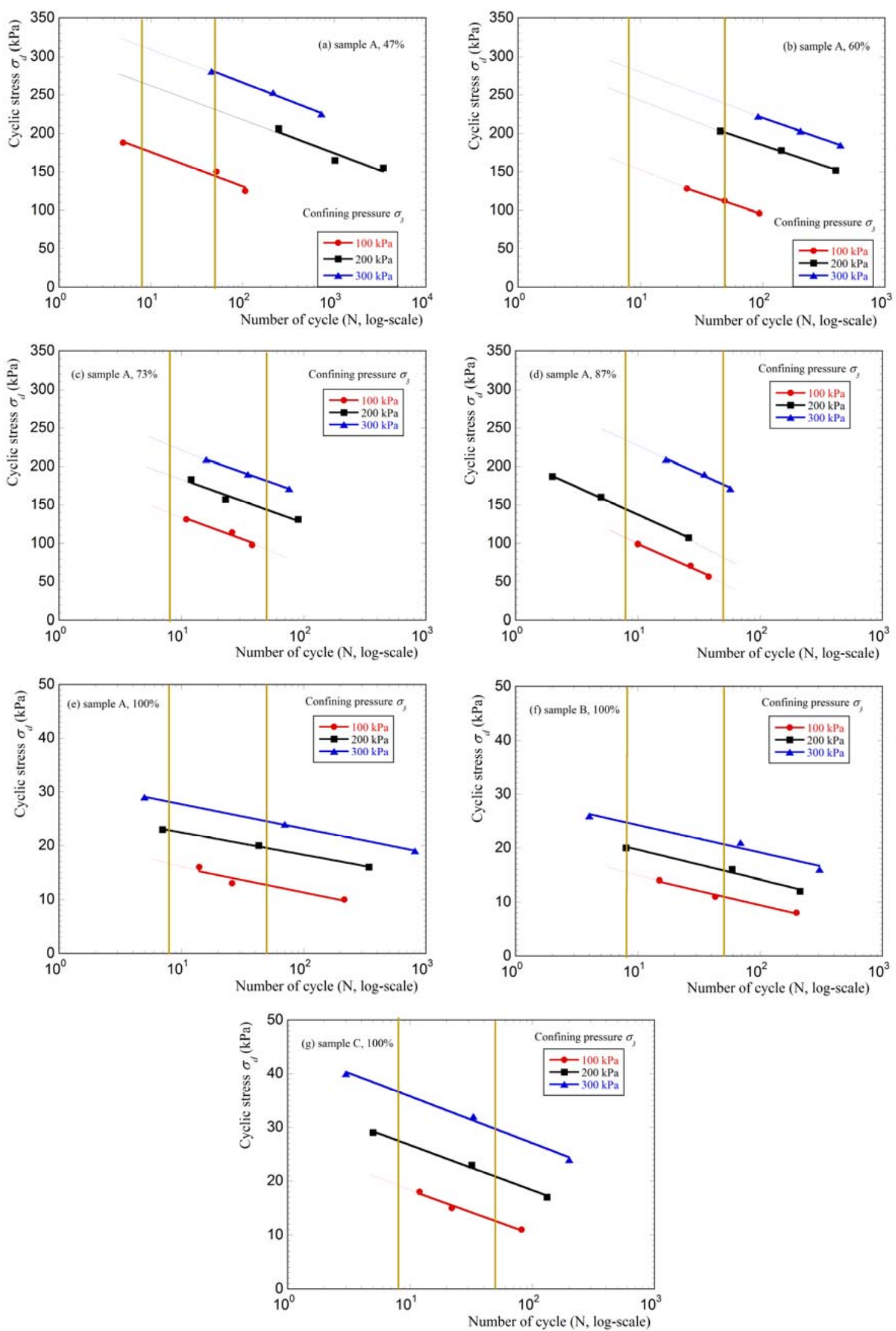

Figure 4 Dynamic strength curves: (a) sample A, 47\%; (b) sample A, 60\%; (c) sample A, 73\%; (d) sample A, $87 \%$; (e) sample A, 100\%; (f) sample B, $100 \%$ and (g) sample C, $100 \%$. 
Table 5 Dynamic shear strength (cohesion and inner friction angle) at different degree of saturation

\begin{tabular}{|c|c|c|c|c|c|c|c|c|}
\hline \multirow{3}{*}{$\begin{array}{l}\text { Nos. of } \\
\text { cycles }\end{array}$} & \multirow{3}{*}{$\begin{array}{l}\text { Shear } \\
\text { strength }\end{array}$} & \multicolumn{7}{|c|}{$\mathrm{SD}(\mathrm{MC})$} \\
\hline & & \multicolumn{5}{|c|}{ Sample A } & Sample B & Sample C \\
\hline & & $47(7)$ & $60(9)$ & 73 (11) & 87 (13) & $100(15)$ & $100(24.7)$ & $100(19.6)$ \\
\hline \multirow{2}{*}{8} & $c_{d}(\mathrm{kPa})$ & 28.3 & 28.9 & 29.0 & 15.0 & 6.07 & 5.3 & 4.2 \\
\hline & $\varphi_{d}\left(^{0}\right)$ & 19.0 & 16.0 & 13.0 & 12.0 & 3.00 & 2.2 & 5.0 \\
\hline \multirow{2}{*}{12} & $c_{d}(\mathrm{kPa})$ & 28.2 & 28.5 & 28.7 & 14.1 & 5.55 & 5.0 & 4.0 \\
\hline & $\varphi_{d}\left({ }^{\circ}\right)$ & 16.0 & 15.0 & 12.0 & 11.0 & 2.80 & 2.1 & 4.6 \\
\hline \multirow{2}{*}{20} & $c_{d}(\mathrm{kPa})$ & 27.3 & 28.1 & 28.0 & 14.0 & 5.45 & 4.6 & $3 \cdot 3$ \\
\hline & $\varphi_{d}\left({ }^{0}\right)$ & 16.0 & 14.0 & 12.0 & 11.0 & 2.80 & 1.9 & 4.0 \\
\hline \multirow{2}{*}{30} & $c_{d}(\mathrm{kPa})$ & 25.1 & 26.7 & $27 \cdot 3$ & 10.7 & 5.24 & 4.3 & 3.1 \\
\hline & $\varphi_{d}\left({ }^{0}\right)$ & 16.0 & 14.0 & 10.0 & 10.0 & 2.40 & 1.3 & 3.7 \\
\hline \multirow{2}{*}{50} & $c_{d}(\mathrm{kPa})$ & 23.2 & 23.4 & 23.4 & 9.6 & 5.00 & 4.0 & 3.0 \\
\hline & $\varphi_{d}\left({ }^{0}\right)$ & 16.0 & 14.0 & 10.0 & 8.0 & 2.20 & 1.1 & 3.2 \\
\hline
\end{tabular}

Notes: (1) The dynamic shear strength is obtained through total stress analysis; (2) MC= Moisture content (\%); $\mathrm{SD}=\mathrm{Degree}$ of saturation (\%); (3) dynamic shear strength, cohesion $c_{d}$ and inner friction angle $\varphi_{d}$.
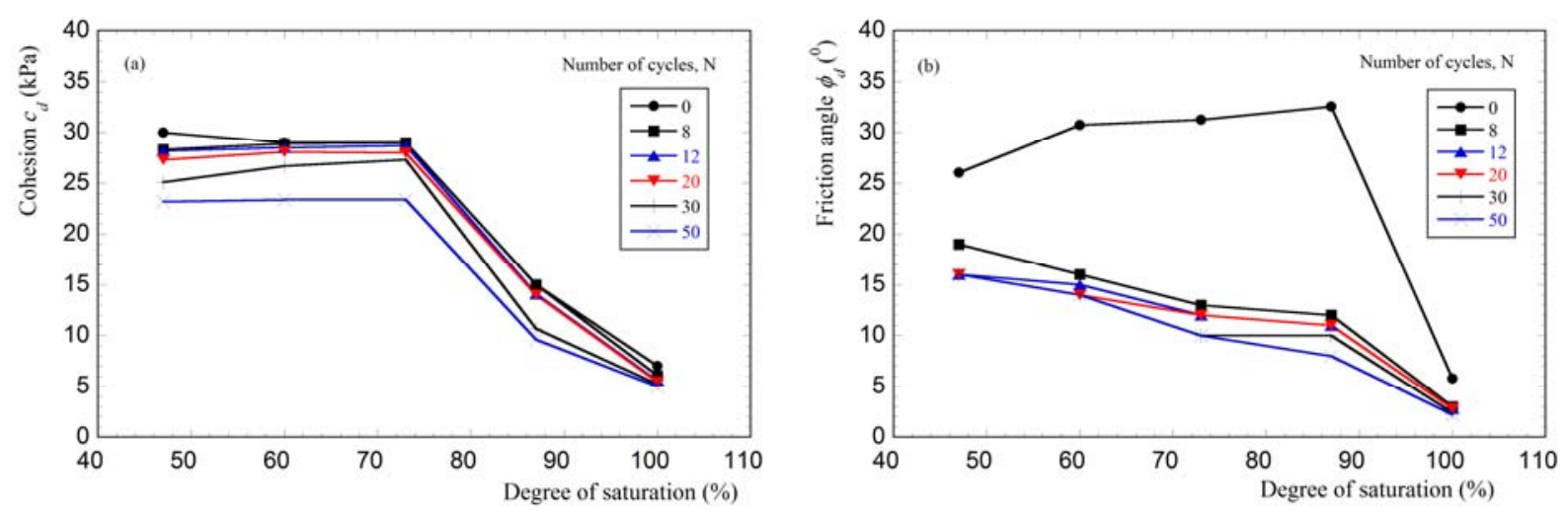

Figure 5 The influence of degree of saturation on the dynamic shear strength of sample A: (a) cohesion $c_{d}$ and (b) inner friction angle $\phi_{d}$.
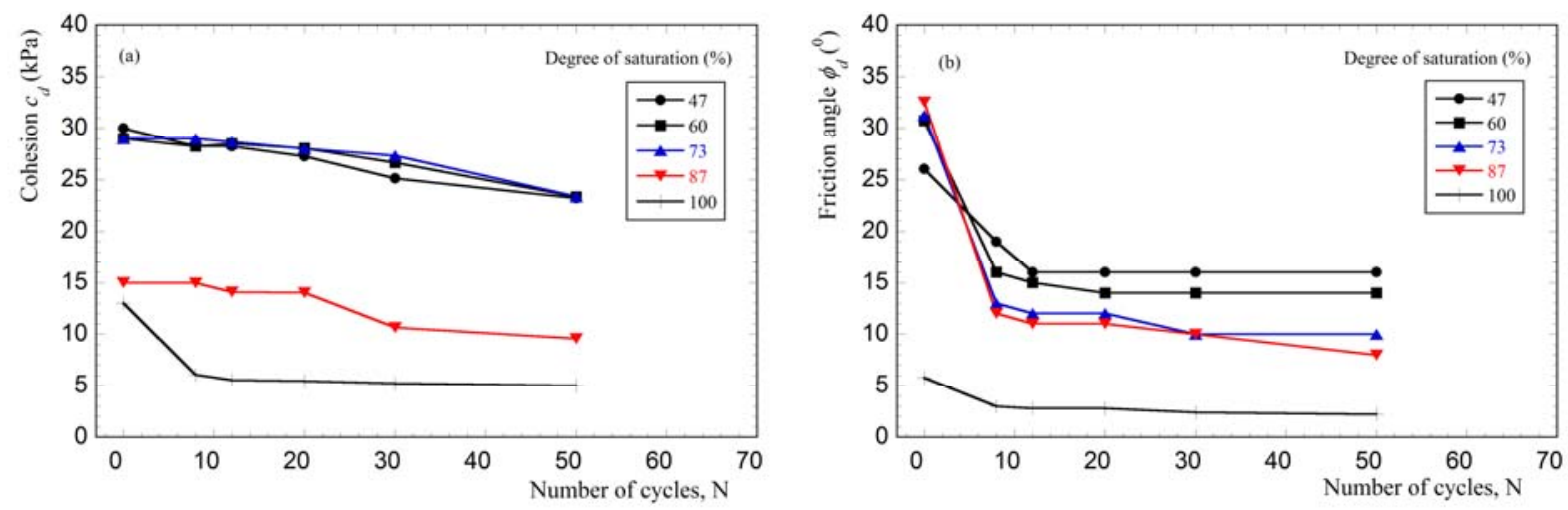

Figure 6 The influence of number of cycles $\mathrm{N}$ on the dynamic shear strength of sample A: (a) cohesion $c_{d}$ and (b) inner friction angle $\phi_{d}$.

and friction angle of sample A is analyzed which differs significantly from that of static shear strength (as shown in Figure 2). The dynamic shear strength of sample A is less than its corresponding static shear strength, and the dynamic friction angle $\left(\phi_{d}\right)$ declines more than dynamic cohesion $\left(c_{d}\right)$ under dynamic loading. Therefore, the resistance to debris flows initiation more depends on inner friction angle rather than on cohesion of soil under the effect of earthquake and rainfall. The declining tendency of dynamic cohesion $\left(c_{d}\right)$ is the same as friction angle $\left(\phi_{d}\right)$ with increase of number of cycles. The dynamic shear strength changes slightly when degree of saturation is less than $73 \%$, but then it 

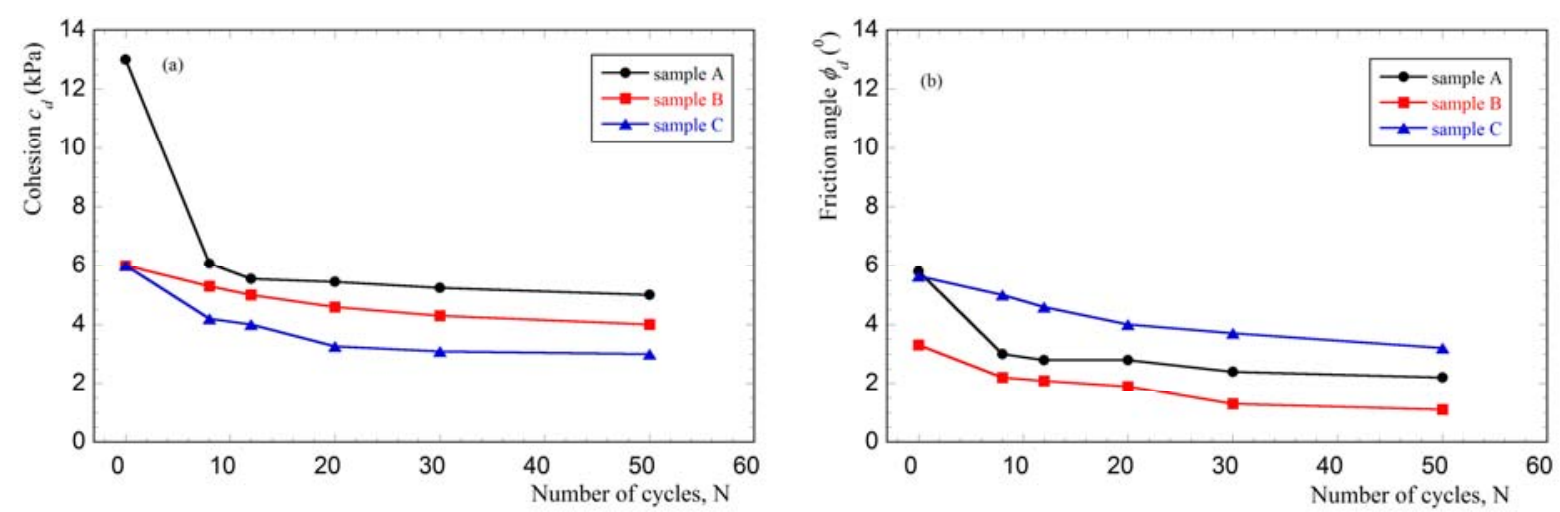

Figure 7 The influence of grain size distribution on the dynamic shear strength: (a) cohesion $c_{d}$ and (b) inner friction angle $\phi$.

quickly decreases with increase of degree of saturation. A speculation is proposed that critical degree of saturation is about $73 \%$ under the effect of earthquake and rainfall.

While dynamic friction angle $\left(\phi_{d}\right)$ keeps decreasing gradually with increase of degree of saturation, it is different from relationship between static friction angle $\left(\phi_{s}\right)$ and degree of saturation. It shows that degree of saturation is a critical parameter for to debris flows initiation. For a soil with high degree of saturation, a slight change in moisture content can cause a considerable decrease in shear strength. But for relatively dry soil, its stability is relatively high even under strong earthquake with high number of cycles. It is found that it is difficult for debris flows to be activated in area because degree of saturation for debris flows initiation is not reached. Liquefaction occurs for soil with high degree of saturation and under strong earthquake, which is easy to activate debris flows.

Figure 6 shows dynamic shear strength $\left(c_{d}\right.$ and $\phi_{d}$ ) of sample A under the influence of earthquake magnitudes. As shown in Figure 6 (a) and Figure 6 (b), the cohesion and friction angle decrease with increase in earthquake magnitude. But their change mechanisms are different. For soil with low degree of saturation, the dynamic cohesion $\left(c_{d}\right)$ decreases gently while for the soil with high degree of saturation, it decreases significantly. From Figure 6 (a) and Figure 6 (b), the high degree of saturation is about $73 \%$. The dynamic shear strength $\left(c_{d}\right.$ and $\left.\phi_{d}\right)$ decreases sharply with increase of number of cycles when degree of saturation is more than $73 \%$. So $73 \%$ is considered to be a critical value. When the number of cycles $\left(\mathrm{N}_{\mathrm{f}}\right)$ is more than 8 (its corresponding earthquake magnitude is greater than M6.5), the dynamic shear strength $\left(c_{d}\right.$ and $\left.\phi_{d}\right)$ of sample A decreases dramatically. It is indicated that debris flows initiation is not dependent on the improvement of earthquake magnitude. The grain size distribution plays an important role in triggering debris flows. Figure 7 shows the relationship between dynamic shear strength $\left(c_{d}\right.$ and $\left.\phi_{d}\right)$ of three saturated samples and the number of cycles. As shown in Figure 7 (a) and Figure 7 (b), the dynamic cohesion $\left(c_{d}\right)$ and dynamic friction angles $\left(\phi_{d}\right)$ decrease gradually with increase in the number of cycles for three saturated samples with different grain size distributions. The dynamic cohesion of sample A is higher than that of sample B and sample $C$ under the same number of cycles. The dynamic friction angles of sample $\mathrm{C}$ and sample $\mathrm{A}$ are higher than that of sample B under the same number of cycles. Therefore, sample B is more likely to activate debris flows than sample $A$ and sample $C$ when they are in completely saturated state under the same earthquake magnitude.

\section{Conclusions}

Through a series of geotechnical tests, the soil shear strength reduction induced debris flows initiation was investigated under the effect of earthquake and rainfall in this study. The relationship between soil shear strength, degree of saturation, number of cycles and grain size distribution was analyzed. Based on a series of test results, the following conclusions were obtained:

(1) The results of laboratory tests show that 
dynamic shear strength of soil is less than its corresponding static shear strength under the effect of earthquake with the same degree of saturation of soils. The strength attenuation varies with degree of saturation, grain size distribution and earthquake magnitudes. Resistance to debris flows initiation more depends on grain interlocking than cohesion of soil under dynamic loading. This possibility is explored through a series of geotechnical tests that debris flows under dynamic loading is more likely to be triggered than under static loading.

(2) Shear strength of slope surface soil decreases gradually with increase of degree of saturation. Debris flows initiation is developed during this humidification process. The earthquake provides energy for debris flows triggering. The geotechnical test results indicate that gravelly soil with a wide and continuous gradation has a critical degree of saturation of approximately $87 \%$, above which debris flows will be initiated. Under the effect of earthquake $(M>6.5)$ and rainfall, the critical degree of saturation is about $73 \%$.

(3) The grain size distribution also plays an important role in triggering debris flows. It may be explained by the fact that loose soil with majority of fine particles is easier to trigger debris flows.

Of course, there are limitations in this study. Three types of different soil samples are prepared based on the grain size distribution of gravelly soils from Weijia Groove debris flows source area. These

\section{References}

Anderson SA, Sitar N (1995) Analysis of rainfall-initiated debris flows. Journal of Geotechnical Engineering 121(7): 544-552. DOI: 10.1061/(ASCE)0733-9410(1995)121:7(544)

Cui P (1992) Studies on condition and mechanism of debris flows by means of experiment. Chinese Science Bulletin 37(9): 759-763.

Cui P (1993) The sudden change properties of debris flows initiation. Journal of Natural Disasters 2(1): pp 53-61.

Cui P, Wei FQ, He SM, et al. (2008) Mountain disaster induced by the earthquake of May 12 in Wenchuan and disasters mitigation. Journal of Mountain Research 26(3):280-282. (In Chinese) DOI 10.1007/s10346-009-0160-9

Cui P, Chen XQ, Zhu YY, et al. (2011) The Wenchuan Earthquake (12 May 2008), Sichuan Province, China and resulting geohazards. Natural Hazard 56(1): 19-36. DOI: 10.1007/s11069-009-9392-1.

Cui P, Zhuang JQ, Cheng XC (2010) Characteristics and countermeasures of debris flows in Wenchuan area after the earthquake. Journal of Sichuan University 42(5): 10-18. (In Chinese)

Cui P, Xiang LZ, Zou Q (2013) Risk assessment of highways affected by debris flows in Wenchuan Earthquake area. soil samples can represent characteristics of typical grain size distribution in debris flows source area but it may not cover the entire characteristics of soils from debris flows source area. So a deviation may still exist between laboratory-prepared soil samples and field-collected soil. A particular attention on field-collected soil will be given to study further. The experimental results in this paper only explore a possibility for debris flows initiation under the effect of earthquake and rainfall based on geotechnical tests. The experimental results provide a comparative analysis for dynamic initiation mechanisms of debris flows in the humidification process for gravelly soil.

\section{Acknowledgements}

This study was sponsored by Natural Science Foundation of China (Grant No. 51269012) and Major Projects of Natural Science Foundation of Inner Mongolia Autonomous Region (Grant No. ZDo602), and it is also part of National Project 973 "Wenchuan Earthquake Mountain Hazards Formation Mechanism and Risk Control" (Grant No. 2008CB425800). The corresponding author was also funded by "New Century Excellent Talents" of University of Ministry of Education of China (Grant No. NCET-11-1016) and China Scholarship Council.

Journal of Mountain Science 10(2): 173-189. DOI: 10.1007/ s11629-013-2575-y.

Chen H, Lee CF (2000) Numerical simulation of debris flows. Canadian Geotechnical Journal 37(1):146-160.

Chen H, Su DI (2001) Geological factors for hazardous debris flows in Hoser, central Taiwan. Environmental Geology 40: 1114-1124. DOI: $10.1007 /$ s002540100312

Chen NS, Cui P, Chen R, et al. (2002) The distribution and characteristics of debris flows along Sino-Nepal highway. Journal of Geological Hazard and Control 13 (1): 44-48. (In Chinese)

Chen H, Lee CF, Relation KT (2004) Causative mechanisms of rainfall-initiated fill slope failures. Journal of Geotechnical and Geoenvironmental Engineering, ASCE 13O(6): 593-602.

Cheng NS, Cui P, Wang XY, Di BF (2004) Testing study on strength reduction of gravelly soil in triggering area of debris flows under earthquake. Chinese Journal of Rock Mechanics and Engineering 23(16): 2743-2747. (In Chinese)

Chen NS, Zhang F (2006) The movement and deposit characteristics of typical catastrophic debris flows by rainstorm in the mountainous area of southwestern China. Scientia Geographica Sinica 26(6): 1-5. 
Chen NS, Zhou W, Yang CL, et al. (2010) The processes and mechanism of failure and debris flows initiation for gravel soil with different clay content. Geomorphology 121: 222-230. DOI: 10.1016/j.geomorph.2010.04.017

Dai F, Lee CF, Wang S (1991) Analysis of rainstorm-initiated slide-debris flows on natural terrain of Lantau Island, Hong Kong. Engineering Geology 51: 279-290.

Dai FC, Lee CF, Wang SJ et al. (1999) Stress-Strain behaviour of a loosely compacted volcanic-derived soil and its significance to rainfall-included fill slope failures. Engineering Geology 53: 359-370.

David RM, Schmidt KM, Dietrich WE, Mckean J (2009) Instrumental record of debris flows initiation during natural rainfall: implications for modeling slope stability. Journal of Geophysical Research: Earth Surface 114: Fo1031. DOI: 10.1029/2008JF001078.

Das BM (2009) Principles of geotechnical engineering. Cengage learning, Stamford, USA.

Fleming RW, Ellen SD, Algus MA (1989) Transformation of dilative and contractive landslide debris into debris flows-An example from Marin County, California. Engineering Geology (Amsterdam) 27: 201-223.

Gregoretti C (2000a) The initiation of debris flows at high slopes: experimental results. Journal of Hydraulic Research 38(2): 83-88. DOI: 10.1080/00221680o09498343.

Gregoretti C (200ob) Experimental evidence from the triggering of debris flows along a granular slope. Journal of Physical and Chemistry on Earth (B) 25(4): 387-390. DOI: 10.1016/S14641909(00)00031-9

Gregoretti, C., Dalla Fontana, G (2008) The triggering of debris flows due to channel-bed failure in some alpine headwater basins of the Dolomites: analyses of critical runoff. Hydrological Processes 22: 2248-2263. DOI: 10.1002/ hyp.6821.

Geotechnical Consulting and Testing Systems (2010) GCTS_STX_100 electro-hydraulic servo control bidirectional dynamic triaxial test system manual. GCTS, Arizona, USA.

Hu MJ, Wang N, Zhang PC (2001) Primary research on the effect of rainfall on landslide-take the slope piled by old landslide in Jianghjiagou valley as example. Journal of Geotechnical Engineering 23(4): 454-457. (In Chinese)

Iverson RM (1997a) The physics of debris flowss. Reviews of Geophysics 35(3): 245-296.

Iverson RM, Reid ME, LaHusen RG (1997b) Debris-flow mobilization from landslides. Annual Review of Earth and Planetary, Sciences 25: 85-138.

Iverson NR, Manna JE, Iverson RM (2010) Effects of soil aggregates on debris-flow mobilization: Results from ringshear experiments. Engineering Geology 114(1-2): 84-92. DOI: 10.1016/j.enggeo.2010.04.006

Kean JW, McCoy SW, Tucker GE, et al. (2013) Runoff-generated debris flowss: observations and modeling of surge initiation, magnitude and frequency. Journal of Geophysical Research 118: 2190-2207.DOI: 10.1029/jgrf20148

Li C, Zhu WH, Lu XB, Cui P (2010) Studied on landslide translating into debris flows under rainfall. Journal of Civil Engineering 43: 371-376. (In Chinese)

Li C, Zhu WH, Lu XB (2013) Study on the seepage-induced debris flow initiation under the rainfall action for slope loose soil. International Association of Chinese Geotechnical Engineers (IACGE): 112-119. DOI: 10.1061/9780784413128.014

Luna BQ, Remaître A, van Asch Th WJ, et al. (2012) Analysis of debris flows behavior with a one dimensional run-out model incorporating entrainment. Engineering Geology 128(9): 6375. DOI: 10.1016/j.enggeo.2011.04.007

Major JJ, Iverson RM (1999) Debris-flow deposition: Effects of pore-fluid pressure and friction concentration at flow margins. Geological Society of America Bulletin 111: 1424-1434.

McCoy SW, Kean JW, Coe JA, et al. (2012). Sediment entrainment by debris flows: In situ measurements from the headwaters of a steep catchment. Journal of Geophysical
Research 117(F3): DOI: 10.1029/2011JFoo2278

Professional Standard of the People's Republic of China (SL2371999). Specifications of Soil Test. China Waterpower Press, Beijing, China. (In Chinese)

Seed HB, Idriss IM (1971) Simplified procedure for evaluating soil liquefaction potential. Journal of the Soil Mechanics and Foundations Division. Journal of the Soil Mechanics and Foundations Division 97(9): 1249-1273.

Sassa K (1984) The mechanism starting liquefied landslides and debris flows. IV Int. Symp Landslides, Toronto, Canada 2, 349-354.

Sladen JA, D'Hollander RD, Krahm J (1985) The liquefaction of sand, a collapse surface approach. Canadian Geotechnical Journal 22(4): 564-578.

Sassa K, Wang GH (2003) Pore-pressure generation and movement of rainfall-initiated landslides: effects of grain size and fine-particle content. Engineering Geology 69(2): 109125.

Takahashi T (1978) The occurrence and flow mechanism of debris flows. Soil Mechanics and Foundation Engineering 26(6): 45-50.

Takahashi T (2007) Debris Flows, Mechanics, Prediction and Countermeasures. Taylar \& Francis Group, London, UK.

Tang C, Liang JT (2008) Characteristics of debris flows in Beichuan epicenter of the Wenchuan Earthquake triggered by rainstorm on September 24, 2008. Journal of Geology Engineering 16(6): 751-758.

Tang C, Zhu J, Li WL, Liang JT (2009) Rainfall-triggered debris flows following the Wenchuan earthquake. Bulletin of Engineering Geology and the Environment 68(2): 187-194. DOI: $10.1007 /$ s10064-009-0201-6:

Wang GH, Sassa K (2003) Pore-pressure generation and movement of rainfall initiated landslides: effects of grain size and fine-particle content. Engineering Geology 69: 109-125. DOI: 10.1016/So013-7952(02)00268-5

Wena BP, Aydinb A (2005) Mechanism of a rainfall-initiated slide-debris flows: Constraints from microstructure of its slip zone. Engineering Geology 78: 69-88.

Wu ZH, Barosh PJ, Zhang ZC, Liao HJ (2012) Effects from the Wenchuan Earthquake and seismic hazard in the Longmenshan Mountains at the eastern margin of the Tibetan Plateau. Engineering Geology (143-144): 28-36. DOI: 10.1016/j.enggeo.2012.06.006

Wang JJ, Zhao D, Liang Y, Wen HB (2013) Angle of repose of landslide debris deposits initiated by 2008 Sichuan Earthquake. Engineering Geology 156(1): 103-110.

Wang J, Zhang H, Tang S, Liang Y (2013) Effects of particle size distribution on shear strength of accumulation soil. Journal of Geotechnical and Geoenvironmental Engineering, DOI: 10.1061/(ASCE)GT.1943-5606.0000931.

Yang CL, Chen NS, Deng MF, Zhou W (2011) Experimental study of the influence of the clay content on the gravel soil mass from the upstream area of a debris flow. Journal of Chengdu University of Technology 38(5): 522-528. (In Chinese)

Zhu JH, Anderson SA (1998) Determination of shear strength of Hawaiian residual soil subjected to rainfall-initiated landslides. Geotechnique 48(1): 73-82.

Zhuang JQ, Cui P, Hu KH, et al. (2010). Characteristic of earthquake-triggered landslides and post-earthquake debris flows in Beichuan county. Journal of Mountain Science 7(3): 246-254. DOI: 10.1007/s11629-010-2016-0

Zhuang JQ (2011) Study the mechanism of debris flows based on field experiment post earthquake environment. Ph. D thesis, Chinese Academy of Sciences. Chengdu, China. (In Chinese)

Zhu WH (2011) Mechanisms of slope instability and the starting of debris-flow under the complex function of rainfall and earthquake. Master thesis, Inner Mongolia University of Technology, Inner Mongolia, China. (In Chinese) 